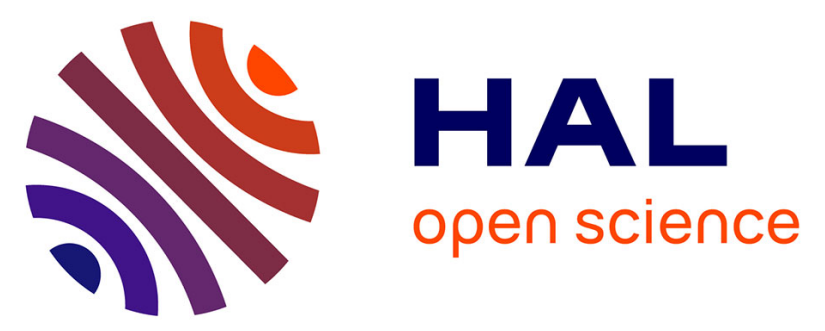

\title{
Off-line and On-line Power Dispatching Strategies for a Grid Connected Commercial Building with Storage Unit
}

Rémy Rigo-Mariani, Bruno Sareni, Xavier Roboam, Stéphan Astier, Jean-Gabriel Steinmetz, Eric Cahuet

\section{- To cite this version:}

Rémy Rigo-Mariani, Bruno Sareni, Xavier Roboam, Stéphan Astier, Jean-Gabriel Steinmetz, et al.. Off-line and On-line Power Dispatching Strategies for a Grid Connected Commercial Building with Storage Unit. 8th Power Plant and Power System Control conference, Sep 2012, Toulouse, France. pp. 266-271. hal-01277590

\section{HAL Id: hal-01277590 \\ https://hal.science/hal-01277590}

Submitted on 22 Feb 2016

HAL is a multi-disciplinary open access archive for the deposit and dissemination of scientific research documents, whether they are published or not. The documents may come from teaching and research institutions in France or abroad, or from public or private research centers.
L'archive ouverte pluridisciplinaire HAL, est destinée au dépôt et à la diffusion de documents scientifiques de niveau recherche, publiés ou non, émanant des établissements d'enseignement et de recherche français ou étrangers, des laboratoires publics ou privés. 


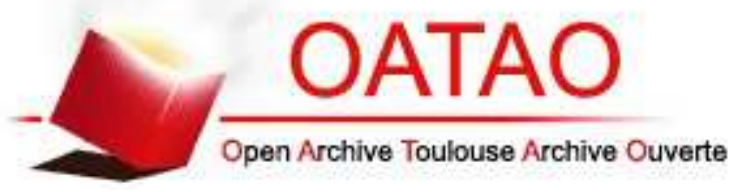

\section{Open Archive TOULOUSE Archive Ouverte (OATAO)}

OATAO is an open access repository that collects the work of Toulouse researchers and makes it freely available over the web where possible.

This is an author-deposited version published in : http://oatao.univ-toulouse.fr/ Eprints ID : 9248

To link to this article : DOI:10.3182/20120902-4-FR-2032.00048

URL : http://dx.doi.org/10.3182/20120902-4-FR-2032.00048

To cite this version :

Rigo-Mariani, Rémy and Sareni, Bruno and Roboam, Xavier and Astier, Stéphan and Steinmetz, Jean-Gabriel and Cahuet, Eric Offline and On-line Power Dispatching Strategies for a Grid Connected Commercial Building with Storage Unit. (2012) In: 8th Power Plant and Power System Control conference, 2-5 sept., 2012, Toulouse, France.

Any correspondence concerning this service should be sent to the repository administrator: staff-oatao@ listes.diff.inp-toulouse.fr 


\title{
Off-line and On-line Power Dispatching Strategies for a Grid Connected Commercial Building with Storage Unit
}

\author{
R. Rigo-Mariani*, B. Sareni*, X. Roboam*, S. Astier*, J.G. Steinmetz**, E. Cahuet** \\ *Universtité de Toulouse, LAPLACE, UMR CNRS-INPT-UPS, site ENSEEIHT, 2 rue Camichel, \\ 31071 Toulouse, France -e-mail: \{rrigo-ma, sareni, roboam, astier\}@laplace.univ-tlse.fr \\ ** SCLE sfe, 25 chemin de Paléficat, 31200 Toulouse, France \\ e-mail: eric.cahuet@scle.fr
}

\begin{abstract}
: with the development of decentralized power sources based on renewable energy, power grids need smarter operations to be run properly. This paper refers to a microgrid with solar panels associated with an energy storage unit connected to the main grid. An off-line optimal dispatching of the storage power flows is proposed in order to minimize energy costs with regards to the daily energy rates. An online management strategy is also introduced so as to control in real-time the grid power predicted over the day by the off-line dispatching.
\end{abstract}

Keywords: smart grid, energy storage, forecasts, power dispatching.

\section{INTRODUCTION}

With the growing population on earth and the new needs that have emerged, global energy consumption has increased by $50 \%$ since the 90's and is expected to keep going up with a ratio of $1.6 \%$ per year ${ }^{1}$. To face the increasing demand of electrical power in compliance with the liberalisation of the electricity market and the need of reducing $\mathrm{CO}_{2}$ emissions, many distributed energy resources have emerged and especially the generation systems that utilize renewable energy sources. Thus distribution networks evolve to a more meshed model, and they are likely to become associations of a large number of "microgrids" (Celli et al, 2004). Due to the stochastic nature of those generations, it requires smarter operations to keep feeding loads in a supply-on-demand system. The improvements in storage technologies allow those operations with a more flexible and reliable management of energy (Yeleti et al, 2010). Renewable energy sources associated with storage units are considered like active distributed generators, one of the fundamental elements of the concept of "Smart Grids"(Lu et al., 2009). Real-time management is required to optimize microgrid operation taking account of forecasts for consumption and generation as well as energy prices (Colson, 2009; Bagherian et al., 2009). This paper refers to a study led in the framework of SMART ZAE project in which French companies and a laboratory are associated. The considered microgrid is presented in Fig. 1:

- A building with a commercial load $-50 \mathrm{~kW} \max$

- PV arrays with a total capacity of $175 \mathrm{~kW}$

- A $100 \mathrm{~kW} / 100 \mathrm{kWh}$ high speed flywheel

The so called "prosumer" is connected to the main grid through two meters with a specific rate when the energy is bought and another one when the production is sold. The goal of the microgrid owner is to control the storage power flows in order to optimize the difference between cost and benefit of the powers flowing through both meters, considering PV production and load consumption forecasts. This economic optimization aims also at predicting the power flows exchanged with grid, for the day ahead. The second objective of the microgrid owner is related to the capacity of fulfilling in real-time this predicted grid power over the day.

The rest of the paper is organized as follows. Section 2 describes the power flow model used to represent the microgrid system. Then, an off-line optimal dispatching of storage powers is introduced in section 3 with the aim of estimating for the day ahead the grid power evolution that minimizes global energy costs. The economic efficiency of the studied microgrid is compared to a corresponding one without storage unit. In section 4, an on-line energy management is proposed in order to ensure in real-time and over the day the fulfilment of the power flowing through the grid. Finally conclusions are drawn in section 5 .

\section{POWER FLOW MODEL}

\subsection{Power flows}

Voltage and current are not considered so far. The study only refers to the optimal dispatching of power flows. Previous work showed that the necessary flows to describe the system strongly depend on the prices policy of the energy feeder and on the position of the meters in the network. In the studied case, with the possibility of selling energy, two flows are required to set the problem (see Fig. 1b), i.e.:

- the power flow $P_{s t \text {-load }}$ exchanged between storage and consumers (i.e. $P_{s t-l o a d}>0$ ) or transferred from grid to storage (i.e. $\left.P_{\text {st-load }}<0\right)$.

- the power flow $P_{p v-s t}$ provided by PV arrays to storage 


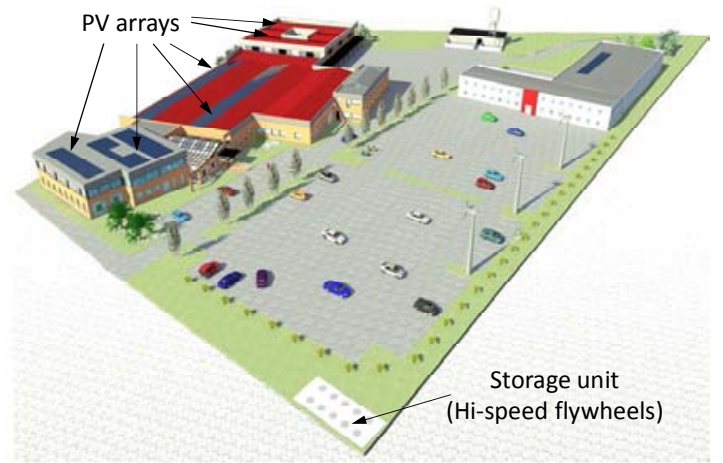

(a) Commercial building with renewable energy production

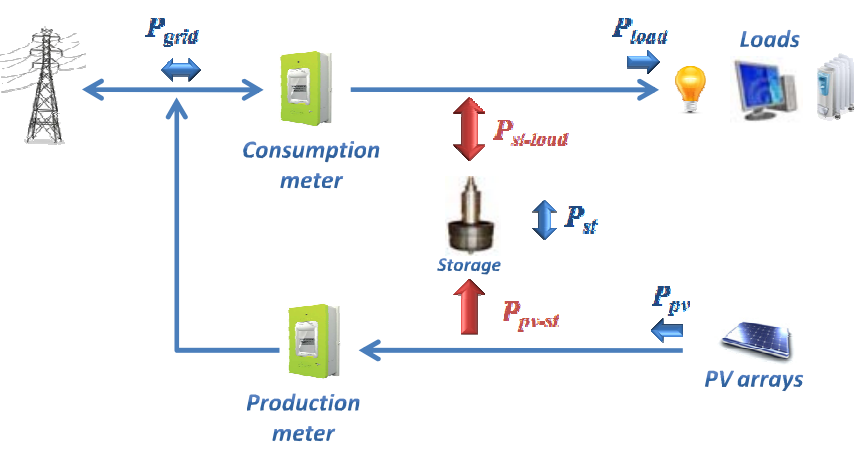

(b) Power flow model

Fig. 1. The studied microgrid.

Those power flows represent the degrees of freedom in the system management. For each elementary time interval $t$, both off-line and on-line operations have to ensure the overall power balance with the storage and the grid considered as generators:

$$
P_{\text {load }}(t)=P_{\text {grid }}(t)+P_{p v}(t)+P_{s t-l o a d}(t)-P_{p v-s t}(t)
$$

\subsection{Storage}

The high speed flywheel is assumed to be a perfect energy storage with no self-discharge. Dynamics are not studied as well as losses within the converters, only the power dispatching being targeted. At each time interval $t$ of duration $\Delta t=600 \mathrm{~s}$, the dispatching strategy has to fulfil the following constraints regarding the storage power and energy:

$$
\begin{aligned}
& P_{s t \text { min }} \leq P_{s t}(t) \leq P_{s t \max } \\
& 0 \leq E_{s t}(t) \leq E_{s t \max }
\end{aligned}
$$

where the storage energy $E_{s t}(t)$ is defined in $\mathrm{kWh}$ as:

$$
E_{s t}(t)=E_{s t}(t-\Delta t)+\left(P_{p v-s t}(t)-P_{s t-l o a d}(t)\right) \frac{\Delta t}{3600}
$$

\subsection{Load and production}

For the load consumption, measurements have been processed on the building for a spring day. That profile is used as real time values. Compiling those data, we build another curve used as forecasts that could be processed the day before (Fig. 2a). Note that the mean squared error normalized by the mean forecast value is about $12 \%$. As a comparison the error performed by the French grid operator (i.e. R.T.E. ${ }^{2}$ ) is about $2 \%$. The production is estimated using a single diode model simplified by a MPPT (Darras et al, 2010).The power is computed with the values of the solar radiation, the temperature and the characteristics of the PV modules.

$P_{p v}\left(G_{i}(t), T_{a}(t)\right)=N_{p v} \frac{G_{i}(t)}{G_{i}^{R}}\left[P_{\max }+\mu_{P \max }\left(T_{j}-T_{j}^{R}\right)\right]$

with $T_{j}=T_{a}(t)+G_{i} \frac{N O C T-20}{800}$

$\mu_{P \max } \quad$ : Power variation with temperature $\left[\mathrm{W} /{ }^{\circ} \mathrm{C}\right]$

$G_{j}^{R} \quad$ : Reference of solar irradiation [W/m²]

NOCT : Normal operating cell temperature [C]

$P_{\max } \quad$ : PV module maximum power [W]

$T_{j}^{R} \quad$ : Module temperature at standard conditions $\left[{ }^{\circ} \mathrm{C}\right]$

$N_{p v} \quad$ : Number of PV modules

The temperature is set to the mean value of the corresponding month. Measurements of solar radiation have been processed in the area of the project for a whole year. Real-time values for a given day are extracted from these data. Forecasts are computed using the absolute position of the sun and the solar panels tilt and orientation (Mehdaoui et al., 2010). The solar energy is adapted every 4 hours during the day to comply with the radiation of the real-time values. Then the following figures are obtained for both loads and production with the forecast used in the off-line operation the day before and realtime values as inputs for the on-line control.
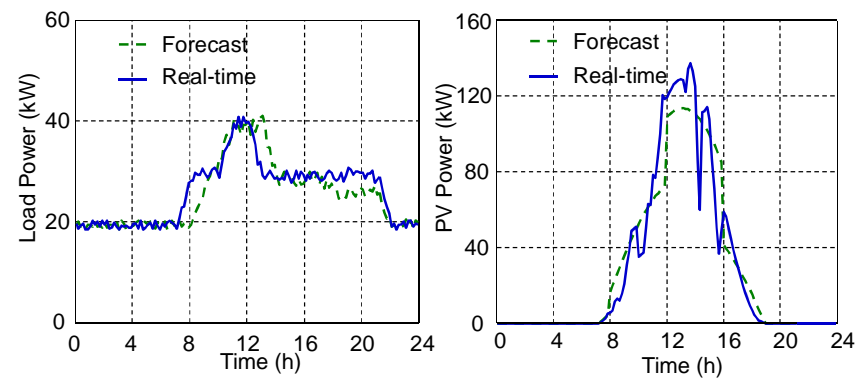

Fig. 2. Difference between forecast and real-time values of load consumption (left) and PV production (right)

\subsection{Rates of the power supplier}

Prices of sold and purchased energies are derived from the rates of the French power supplier:

- $C_{\text {purchase }}=0.13 € / \mathrm{kWh}$ from 6 a.m. to 10 p.m.

- $C_{\text {purchase }}=0.08 € / \mathrm{kWh}$ from 10 p.m. to 6 a.m.

- $C_{\text {sale }}=0.45 € / \mathrm{kWh}$

It corresponds to a case in which selling PV electricity remains very interesting in order to favour the development of renewable energy sources. Another case is also considered with no gain on PV production (i.e. $C_{\text {sale }}=0 € / \mathrm{kWh}$ ) aiming at encouraging self-consumption. 


\section{OPTIMAL OFF-LINE DISPATCHING OF STORAGE POWER FLOWS}

In this section, a power dispatching strategy is investigated for a suitable use of the storage unit. It consists in determining the optimal references for the storage power flows (i.e. $P_{p v \text {-st }}^{*}(t)$ and $\left.P_{s t \text {-load }}^{*}(t)\right)$ that ensure the lowest daily energy cost (or the higher daily energy benefit) for given production and consumption. The optimal dispatching is formulated into a standard non-linear and constrained optimization problem.

\subsection{Decision variables, upper and lower bounds}

$P_{p v-s t}(t)$ and $P_{s t-l o a d}(t)$ constitute the decision variables of the optimal dispatching strategy. All power flows in the system are sampled with a period of $600 \mathrm{~s}$. Consequently, 144 unknowns for each storage flows on the overall day have to be determined, leading to a total number of decision variables of 288. Upper and lower bounds of those variables are obtained from power storage limits represented by (2) and operating constraints ensuring that no power in the flywheel is returned to the grid:

$$
\begin{aligned}
& P_{s t \text { min }} \leq P_{s t-l o a d}(t) \leq \min \left(P_{s t \max }, P_{\text {load }}(t)\right) \\
& 0 \leq P_{p v-s t}(t) \leq \min \left(P_{s t \max }, P_{p v}(t)\right)
\end{aligned}
$$

\subsection{Objective function}

As referred above, the objective is to minimize energy cost regarding both purchased and sold energies. The purchased energy cost $C_{P}$ on the overall day is expressed as:

$$
C_{p}=C_{\text {purchase }} \sum_{t=1}^{144}\left(P_{\text {load }}(t)-P_{\text {st-load }}(t)\right) \frac{\Delta t}{3600}
$$

while the gain $G_{s}$ in energy production returned to the grid is defined as:

$$
G_{s}=C_{\text {sale }} \sum_{t=1}^{144}\left(P_{p v}(t)-P_{p v-s t}(t)\right) \frac{\Delta t}{3600}
$$

Finally, the objective function to be minimized is the global energy cost $C_{E}$ defined as the difference between the purchased energy cost and the sold energy gain:

$$
C_{E}=C_{p}-G_{s}
$$

\subsection{Non-linear constraints}

Additional constraints on the storage unit have to be considered in order to ensure a good system operating. In particular, two inequality constraints on the storage energy are introduced to avoid overcharge or overdischarge during the day:

$$
G_{\text {overcharge }}=\sum_{t=1}^{144} \max \left(0, E_{s t}(t)-E_{s t \max }\right) \leq 0
$$

$G_{\text {overdischarge }}=\sum_{t=1}^{144} \max \left(0, E_{s t \min }-E_{s t}(t)\right) \leq 0$

where $E_{s t \min }$ and $E_{s t \max }$ respectively denote the energy storage corresponding to the minimum and maximum allowed state of charge (in our case $E_{s t \min }=0 \mathrm{kWh}$ and $E_{s t \max }=100 \mathrm{kWh}$ ).

Finally, the following equality constraint is also incorporated in order to impose that the storage energy state at the end of the day returns to its initial state, i.e.

$$
E_{s t}(144)=E_{s t}(0)=50 \mathrm{kWh}
$$

All these constraints are related to the storage energy. Remind that power limits on the storage are always guaranteed by upper and lower bounds of the decision variables defined in the previous subsection.

\subsection{Tests and results}

The optimal dispatching consists in solving the non-linear constrained optimization problem defined as the minimization of the global energy cost (10) while fulfilling energy constraints (11), (12) and (13). Decision variables are the storage power flows $P_{s t \text {-load }}$ and $P_{p v \text {-load }}$ for which upper and lower bounds (6) and (7) ensure storage power limits and load consumption for a given PV production. The problem can be easily solved using non-linear optimization methods such as sequential quadratic programming, through the use of fmincon Matlab function.

We illustrate the off-line dispatching strategy considering the forecast production and consumption of Fig. 2 for both cases of PV electricity selling previously mentioned. In each case, the optimal solution is compared to a solution without storage where all the PV production flows through the production meter and where the load is only fed by the grid through the consumption meter.

Table 1. Results of optimal dispatching for $C_{\text {sale }}=0.45 € / \mathrm{kWh}$

\begin{tabular}{|c|c|c|}
\hline & without storage & with storage and optimal dispatching \\
\hline$C_{p}$ & $72.0 €$ & $66.9 €$ \\
\hline$G_{s}$ & $309.9 €$ & $309.9 €$ \\
\hline$C_{E}$ & $-237.9 €$ & $-242.6 €$ \\
\hline
\end{tabular}

In the first case, the rate of the sold energy is so high compared to the cost of the purchased electricity that all the production has to go up to the grid. There is no interest to transfer PV energy to the storage unit and $P_{p v-s t}$ remains null over the day. However, five Euros can be saved compared to a system without storage unit by exploiting the variable rate of energy consumption during the day (see Table 1). It can be seen from Fig. 3 that $P_{\text {st-load }}<0$ up to 6 a.m. This indicates that the storage is charged from the grid when the consumption rate is low. When the energy cost increases at 6 a.m., the load is fed by the flywheel in order to reduce as much as possible the power flowing through the consumption meter. 

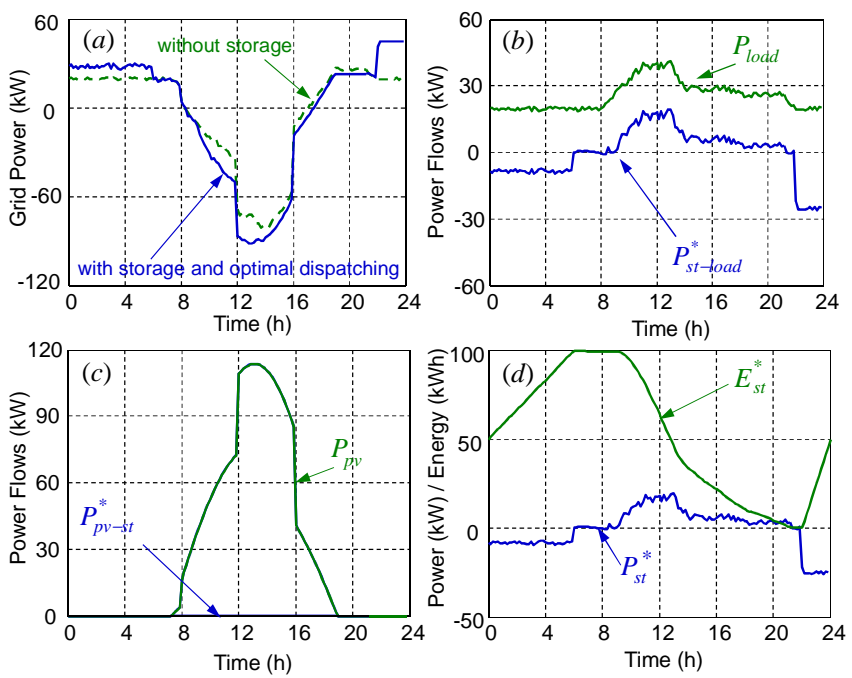

Fig. 3. Optimal dispatching results for $C_{\text {sale }}=0.45 € / \mathrm{kWh}$

In the second case with $C_{\text {sale }}=0 € / \mathrm{kWh}$, there is no interest to sold the production. Two degrees of freedom offered by the storage unit can be used for minimizing the purchased energy, allowing a decrement by $73 \%$ of the total cost in comparison with a system without storage (see Table 2 ). The storage contributes to feed the load between 0 and 6 a.m. (see Fig. $4 b$ ). During day time the great level of PV production supplies the load while loading the flywheel. There is still some energy surplus flowing though the production meter and returned to the main grid. Compared to the previous situation, both storage flows evolve in order to optimize the global energy cost.

Table. 2 Results for $C_{\text {sale }}=0 € / \mathrm{kWh}$

\begin{tabular}{|c|c|c|}
\hline & without storage & with storage and optimal dispatching \\
\hline$C_{p}$ & $72.0 €$ & $23.9 €$ \\
\hline$G_{s}$ & $0 €$ & $0 €$ \\
\hline$C_{E}$ & $72.0 €$ & $23.9 €$ \\
\hline
\end{tabular}
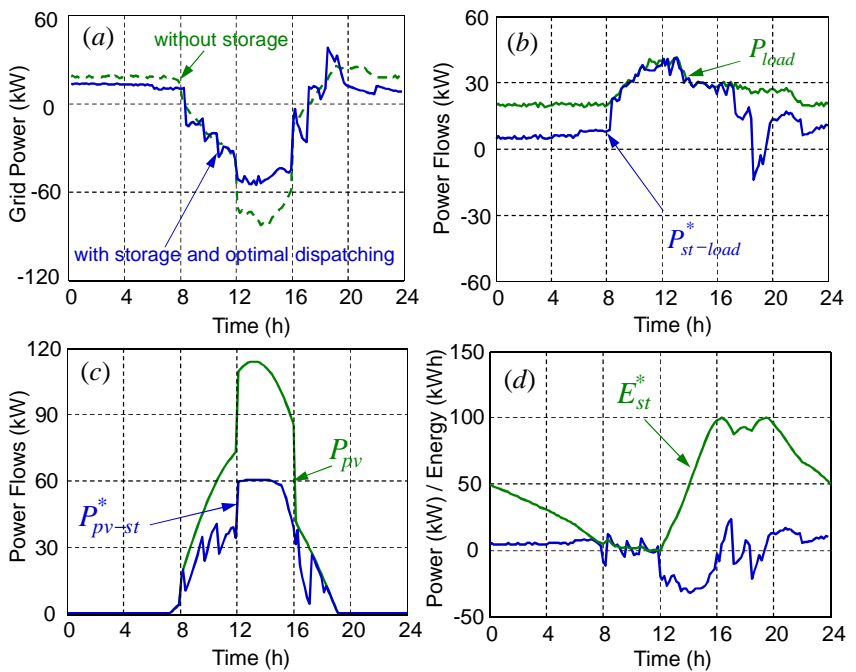

Fig. 4. Optimal dispatching results for $C_{\text {sale }}=0 € / \mathrm{kWh}$

\section{ON-LINE OPERATION}

\subsection{Principle}

The off-line power dispatching developed in the previous section estimates for the day ahead the optimal power flow $\widehat{P}_{\text {grid }}$ exchanged with the grid over the day. It appears difficult to foresee the future expectations of the governments and power suppliers towards the prosumer. However, judging from the laws that appear in recent years with the development of decentralized energy sources, forecasting the profile of the power flowing though the grid is likely to become one of the most important concerns in terms of valuable grid services. Thus in real time, by taking account of forecasting errors, the on-line energy management strategy consists in controlling the storage power flows (i.e. $P_{\text {st-load }}$ and $\left.P_{p v \text {-load }}\right)$ so that the grid power over the day $P_{\text {grid }}$ would be as close as possible as the predicted profile $\left(\widehat{P}_{\text {grid }}\right)$. Obviously the performance of such control strongly depends on the quality of the forecasts (Potter et al., 2009). Consequently, a tolerance $\Delta P$ in terms of power deviations from the reference $\widehat{P}_{\text {grid }}$ is considered, defining a bandwidth $\widehat{P}_{\text {grid }} \pm \Delta P$ for which errors between predicted and actual grid power flows remain acceptable. It should be noted that $\Delta P$ can be set by the microgrid owner or imposed by the power supplier. The real-time control strategy investigated in this paper acts as follows: for each elementary time interval $t$, the grid power $P_{\text {grid }}(t)$ and the storage energy $E_{s t}(t)$ are computed from the actual PV production $P_{p v}(t)$, the actual load consumption $P_{\text {load }}(t)$ and the predicted storage powers $\widehat{P}_{\text {st-load }}(t)$ and $\widehat{P}_{p v-s t}(t)$ according to (14) and (15) :

$$
\begin{aligned}
& P_{\text {grid }}(t)=P_{\text {load }}(t)-P_{p v}(t)-\widehat{P}_{s t-l o a d}(t)+\widehat{P}_{p v-s t}(t) \\
& E_{s t}(t)=E_{s t}(t-\Delta t)+\left(\hat{P}_{p v-s t}(t)-\widehat{P}_{s t-l o a d}(t)\right) \frac{\Delta t}{3600}
\end{aligned}
$$

Then, four cases have to be distinguished according to the value of $P_{\text {grid }}(t)$ in (14):

- Case 1: if $\left|P_{\text {grid }}(t)-\widehat{P}_{\text {grid }}(t)\right|>\Delta P$ and $0 \leq E_{s t}(t) \leq E_{s t \text { max }}$, the actual storage powers are optimized in order to set the actual grid power on the limit of the bandwidth, i.e.

$$
P_{p v-s t}^{*}(t), P_{s t-l o a d}^{*}(t)=\arg \min \left(\left|P_{\text {grid }}(t)-\hat{P}_{\text {grid }}(t) \pm \Delta P\right|\right)
$$

- Case 2: if $\left|P_{\text {grid }}(t)-\widehat{P}_{\text {grid }}(t)\right|<\Delta P$ and $0 \leq E_{s t}(t) \leq E_{s t \max }$ the procedure aims at correcting the deviations of the storage energy, i.e:

$$
P_{p v-s t}^{*}(t), P_{s t-l o a d}^{*}(t)=\arg \min \left(\mid E_{s t}(t)-E_{s t}^{*}(t)\right)
$$

Case 3: if $E_{s t}(t)<E_{s t m i n}$ the constraint on the energy storage has to be fulfilled:

$$
P_{p v-s t}^{*}(t), P_{s t-l o a d}^{*}(t)=\arg \min \left(\left|E_{s t}(t)-E_{s t \min }(t)\right|\right)
$$

- Case 4: if $E_{s t}(t)>E_{s t \max }$ the problem is similar to the previous case:

$$
P_{p v-s t}^{*}(t), P_{s t-l o a d}^{*}(t)=\arg \min \left(\left|E_{s t}(t)-E_{s t \max }(t)\right|\right)
$$


The determination of $P_{p v-s t}^{*}(t)$ and $P_{s t-l o a d}^{*}(t)$ in (16), (17), (18) and (19) is performed with a simple greedy algorithm consisting in the successive exploration a $2 \mathrm{D}$ neighbourhood with a step size of $0.1 \mathrm{~kW}$ on each direction (see Fig. 5). The reference point is refreshed every generation by determining the best solution in the neighbourhood that minimizes the objective function related to the considered case.

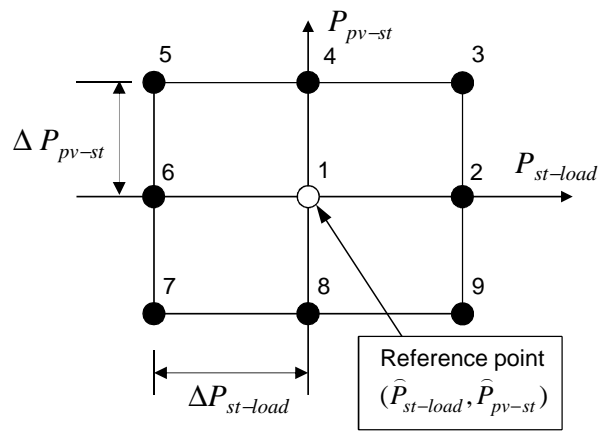

Fig. 5. Grid used for exploring the $2 \mathrm{D}$ neighbourhood at initial iteration

The search starts from the initial point $\widehat{P}_{s t-l o a d}(t)$ and $\widehat{P}_{p v-s t}(t)$ issued from the off-line power dispatching and goes on until no improvement on the objective function is met. Note that some points could be automatically discarded if they lead to a violation of the constraints associated with the storage power and energy (i.e. equations (2), (3), (6) and (7)). An additional constraint is introduced in the case 2 in order to guarantee a resulting grid power inside the bandwidth. Finally, it should be noted that in the case 1 , the optimal point resulting from minimization of (16) might not reach the bandwidth limit. In such case, load shedding on the consumption can be performed by the microgrid owner in order to ensure the fulfilment of the predicted grid power $\widehat{P}_{\text {grid }}$. The reduction of the load consumption constitutes an additional degree of freedom in the energy management strategy related to a trade-off between the continuity of load services and the grid power requirements. The capacity of derating the consumption strongly depends on the consumer nature. In our case, it has been assumed that the maximum duration of a power cut is identical to the minimum period allowed between two successive power cuts, i.e: $T_{O N}=T_{O F F}=30 \mathrm{~min}$. The power derates are also limited to a value $P_{\text {cutmax }}=15 \mathrm{~kW}$.

\subsection{Performance criteria}

In this subsection, some performance criteria are introduced in order to quantify the error between an effective grid power profile $P_{\text {grid }}^{*}(t)$ and a given predictive reference $\widehat{P}_{\text {grid }}$ (see Table 3 ). These criteria are calculated over the day according to Fig. 6.

Table. 3 Performance criteria

\begin{tabular}{|c|c|c|}
\hline$\sigma$ & Root mean square error & $\mathrm{kW}$ \\
\hline$\sigma_{\max }$ & Maximum deviation & $\mathrm{kW}$ \\
\hline$N_{o v}$ & Number of overshoots & - \\
\hline$T_{o v}$ & Total overshoot duration & $\mathrm{h}$ \\
\hline$E_{o v}$ & Total energy during overshoots & $\mathrm{kWh}$ \\
\hline
\end{tabular}

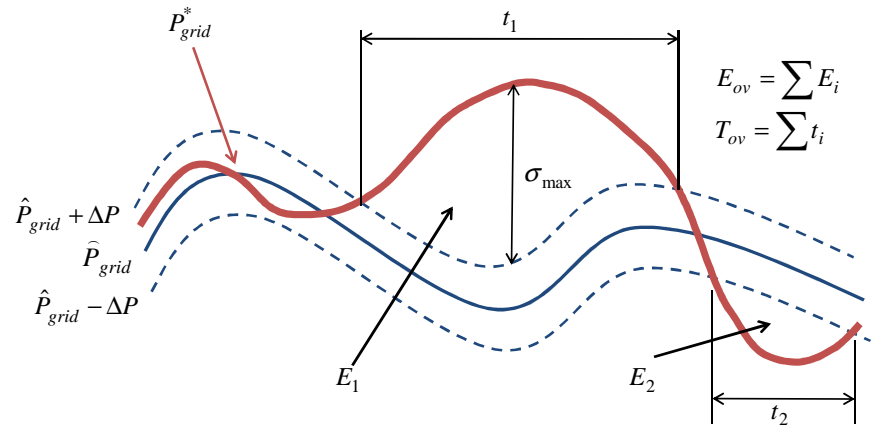

Fig. 6. Illustration of the performance criteria

\subsection{Tests and results}

The on-line control strategy is applied using the reference given by the off-line power dispatching for $C_{\text {sale }}=0 € / \mathrm{kWh}$ considering the real-time values of the consumption and PV production in Fig. 2. As explained before, the main objective is to maintain $P_{\text {grid }}$ as close as possible to the reference $\widehat{P}_{\text {grid }}$ within a bandwidth $\pm \Delta P$. The performance criteria defined in the previous subsection are then compared between a situation with no adaptation (i.e. when the storage power flows predicted from the off-line dispatching are used as control references) and a case where the on-line management strategy is processed with a tolerance bandwidth of $\Delta P=10 \mathrm{~kW}$. Quantitative results are given in Table 4.

Table. 4 Performance criteria with and without the online control of storage powers

\begin{tabular}{|c|c|c|}
\hline & Without on-line control & With on-line control \\
\hline$\sigma$ & $8.9 \mathrm{~kW}$ & $5.3 \mathrm{~kW}$ \\
\hline$\sigma_{\max }$ & $44.3 \mathrm{~kW}$ & $34 \mathrm{~kW}$ \\
\hline$N_{o v}$ & 9 & 6 \\
\hline$T_{o v}$ & $6 \mathrm{~h} 10 \mathrm{~min}$ & $2 \mathrm{~h} 48 \mathrm{~min}$ \\
\hline$E_{o v}$ & $86 \mathrm{kWh}$ & $38 \mathrm{kWh}$ \\
\hline
\end{tabular}

Figure $7 a$ clearly shows the advantages of the on-line control strategy which reduces the overshoot impacts compared to the use of the references issued from the off-line power dispatching. We can see from Table 4 that all performance criteria are significantly improved. It should also be noted that the largest overshoots occur in the afternoon (at around 3 p.m.) when the storage is fully charged by the important PV production. In practical, those overshoots could be avoided by derating PV production through MPPT control of PV arrays. Fig. $7 b$ and Fig. $7 c$ particularly illustrate the adaptation of the storage power flows for ensuring the grid power requirements in relation to forecast errors. This leads to some deviations on the storage power $P_{s t}^{*}$ and the associated energy $E_{s t}^{*}$ (Fig. $7 d$ and Fig $7 e$ ) in comparison with the corresponding values predicted by the off-line power dispatching. However, this does not really affect the economic efficiency of the microgrid. The daily energy cost related to forecast errors and computed from the grid power obtained with the on-line control strategy is of $38 €$. This cost is a little bit higher than the optimal energy cost determined by the off-line dispatching (i.e. $23.9 €$ ) but still more interesting than the energy cost of a system without storage (i.e.72€). 

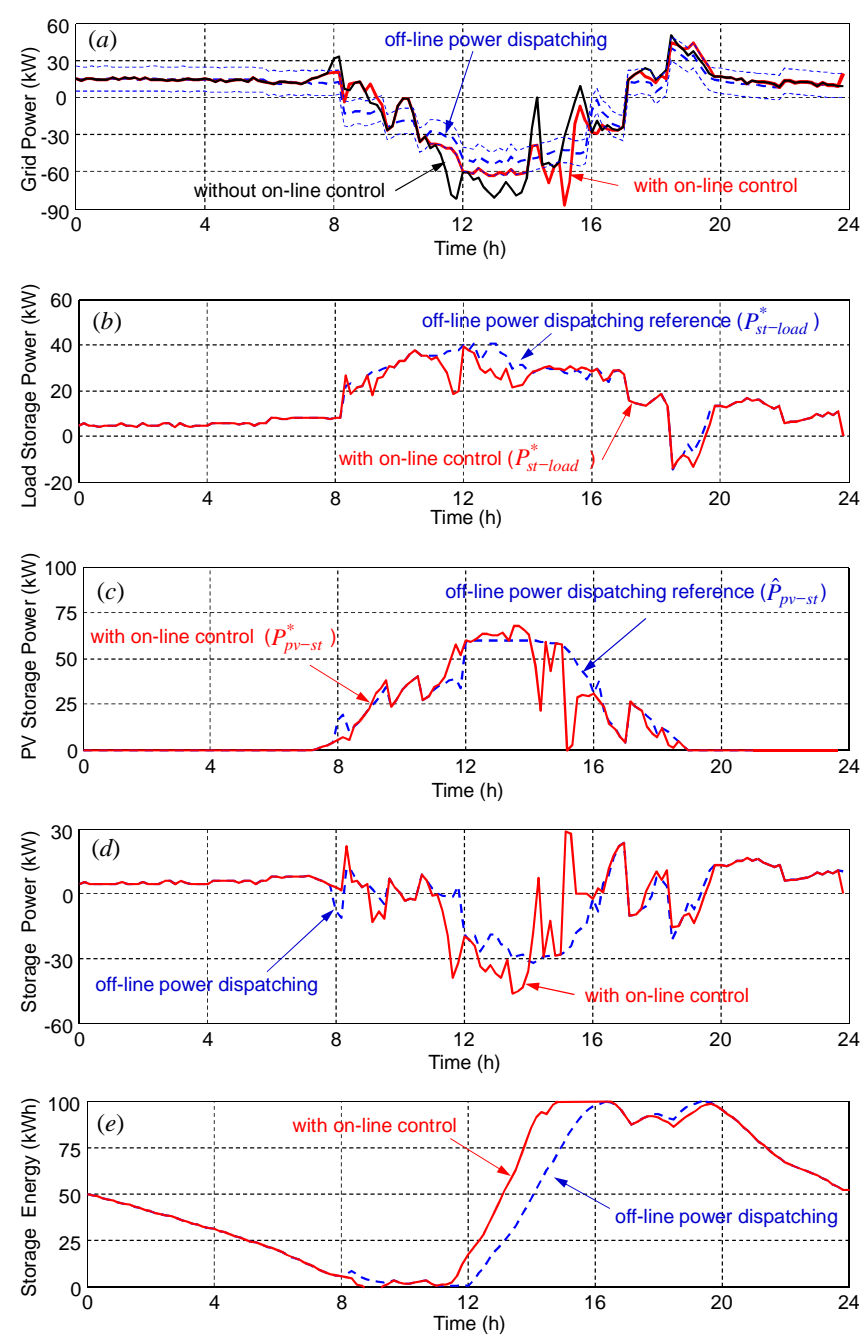

Fig. 7. Results obtained with the on-line control strategy

\section{CONCLUSIONS}

In this paper, off-line and on-line management strategies for a microgid with storage have been proposed. It has been shown that the cooperative use of those strategies reduces the cost of the energy consumption while taking account of forecast errors and grid power requirements imposed by the power supplier. It should be noted that some approximations have been done, especially concerning the behaviour of the storage unit and the losses within the various power converters. Moreover, the electrical architecture of the microgrid has not been considered in the model. In the future, all those features should be integrated for a better quantification of economic gains but it will not change our approach of energy management.

Further works will also investigate the generalization of our approach for more complex microgrid architectures including other parameters, e.g. multiple energy storages of different nature (flywheels, fuel cells, batteries), various energy rates related to the cost of the grid power depending on the target load (storage charge or consumer feeding) and other grid services such as peak shaving or grid disconnection.
Finally, additional studies will focus on the coupling between the sizing of the storage and the energy management aiming at optimizing the trade-off between the cost of the storage systems and the reduction of the microgrid energy consumption.

\section{REFERENCES}

Bagherian, A., Moghaddas, S.M. (2009). A developed Energy Management System for a Microgrid in the Competitive Electricity Market. IEEE Bucharest Power Tech Conference, Bucharest, Romania.

Celli, G., Pilo, F., Pisano, G., Allegranza,V., Cicoria, R., Iaria, A. (2004). Meshed vs. radial MV distribution network in presence of large amount of DG. Power Systems Conference and Exposition, 2004. IEEE PES.

Colson, C.M., (2009).A Review of Challenges to Real-Time Power Management of Microgrids. IEEE Power \& Energy Society General Meeting, 1-8.

Darras, C., Sailler, S., Thibault, C., Muselli, M., Poggi, P., Hoguet, J.C., Melsco, S., Pinton, E., Grehant, S., Gailly, F., Turpin, C., Astier, S., Fontès, G., (2010). Sizing of photovoltaic system coupled with hydrogen/oxygen storage based on the ORIENTE model. International Journal of Hydrogen Energy.

Lu, D., François, B., (2009). Strategic Framework of an Energy Management of a Microgrid with a Photovoltaic-Based Active Generator. ELECTROMOTION 2009 - EPE Chapter 'Electric Drives' Joint Symposium, Lille, France.

Mehdaoui, A., Sadok, M., Chikhi, S.A., Mammeri, A., (2010). Gain énergétique entre deux configurations de système de pompage d'eau photovoltaïque Application au site d'Adrar. Revue des Energies Renouvelables, Vol. $13 \mathrm{~N}^{\circ} 4.571-582$

Potter, C.W., Archambault, A., Westrick, K. (2009). Building a Smarter Smart Grid Through Better Renewable Energy Information. In Proc. Power Systems Conference and Exposition, 1-5.

Yeleti, S., Yong Fu (2010). Impacts of energy storage on the future power system. North American Power Symposium (NAPS), 1-7.

\section{Websites: ${ }^{1}$ http://www.eia.gov \\ 2 http://www.rte-france.com \\ ${ }^{3}$ http://www.siliken.com}

\section{AKNOWLEDGMENT}

This study has been carried out in the framework of the SMART ZAE national project supported by ADEME (Agence de l'Environnement et de la Maîtrise de l'Energie). The authors thank SCLE, LEVISYS and CIRTEM for their cooperation and Colomiers high school for providing the data of solar irradiation. 